\title{
Exploring the role of data-supported social interaction manifested through public displays
}

\section{Yuhan Ji}

The Bartlett, UCL

London, United Kingdom

yuhan.ji.16@ucl.ac.uk
Ava Fatah gen. Schieck

The Bartlett, UCL

London, United Kingdom

ava.fatah@ucl.ac.uk

\section{Abstract}

This paper presents the early findings of studies in the role of data informing the interaction between the user, public and public display. It focuses on exploring how different strategies amplify and stimulate these datasupported interactions. Building on the work by Tomisch et al (13), we establish a taxonomy for databased features under the category of key elements in urban visualisations: 1 ) addressed topics, 2 ) input technologies, and 3) visualisation output. We analyse how these factors facilitate social interactions meaningfully through case studies of previous projects developed and implemented by Media Architecture

Paste the appropriate copyright/license statement here. ACM now supports three different publication options:

- ACM copyright: ACM holds the copyright on the work. This is the historical approach.

- License: The author(s) retain copyright, but ACM receives an exclusive publication license.

- Open Access: The author(s) wish to pay for the work to be open access. The additional fee must be paid to ACM.

This text field is large enough to hold the appropriate release statement assuming it is single-spaced in Verdana 7 point font. Please do not change the size of this text box.

Each submission will be assigned a unique DOI string to be included here.

research community. We suggest that data properties and manifestation play a significant role in 1) sustaining attraction to passers-by 2) enriching public

understandings of display, and 3) encouraging diverse participation.

\section{Author Keywords}

public displays, data property and manifestation, social interaction, perceptional and behavioural changes.

\section{ACM Classification Keywords}

H.5.m. Information interfaces and presentation (e.g., HCI): Miscellaneous; See

http://acm.org/about/class/1998 for the full list of ACM classifiers. This section is required.

\section{Introduction}

The urban environment is increasingly mediated through the pervasive and emerging $\mathrm{HCI}$ technologies. Within the context of interactive public displays, researchers have provided rich insights in revealing how featured display configurations support social relationship, yet the relationship data itself on shared experiences between participants and the public still need to be clarified. In this paper, we aim to address 1 ) what is the factors that influence the social interactions and 2) how these factors support different types of 
social interaction meaningfully. In order to explore these questions, we conducted a literature review to confirm the key factors, and case studies in several relevant projects to identify the perceptional and behavioural influence on participation. We explore the data properties and manifestation in framing and supporting public engagement. In particular, the criteria will be structured through existing bodies of ambient display taxonomies proposed by Pousman and Stasko (12), and Tomitsch et al (13), with a specific perspective in the input and display of information. We focus on 1) the taxonomy of data-related features in ambient display (information capacity, localness, and etc.) and 2) the type of augmented public interaction. Our findings are discussed in regard to social relationships and stress the perceptional and behavioural aspects of interaction.

\section{Background Research}

In the light of data contribution, Koeman (6) defined three key elements of information visualisations: 1 ) addressed topics 2) input technologies and 3 ) visualisation output. Under these the category, we identify and categorise the data-related features based on the previous study.

Extensive research has carried out to build a taxonomy of various features in ambient display. Matthew et al (7) firstly proposed three key characteristics of ambient display with a focus on the "peripherality", namely: abstraction of data, selection of notification levels, and transitions between notification levels. Based on the pioneering work, Pousman and Stasko (12) emphasise on the display of information and add "information capacity", "aesthetic emphasis" to the design dimensions of the display. They plot each dimension with five modes from "high" to "low". Tomitsch et al (13) further expand these dimensions into a more specific taxonomy with nine characteristics in the matter of data manifestation.

Several projects contributed to identifying the data attributes that influence social interaction. Netto et al proposed three layers of information-physical, semantic and enacted, according to their description, physical information represents the facts of environment, after interpretation it transfers into the semantic content, and enacted information play as the consequence for direct public use (9). In other aspects, Cleas and Vande Moore (3), and Wouters et al (17) outline that hyperlocality of information have an impact on public awareness and participation. The more relevant of the topic within the situated context, the more attention and understandings will be gained from public.

\section{Framework of the Criteria}

Based on previous studies (7)(12)(13), we build on previous work and suggest a taxonomy of key features in an interactive public display regarding to their correlation with data:

\section{Addressed topics}

1. Information content- The meaningfulness of input data: physical, semantic and customised. The definition of first two layers is similar to Netto et al (9), and customised information refers to free content created by participants.

2. Hyperlocality of topic- Social relevance between the topic and the situated context. Metrics: irrelevant, communal, hyperlocal. 
Input Technologies

1. Input action- Input mechanism and behaviour of participants to submit the data.

2.User interface- Type of tangible user interface. Metrics is based on the work by Hespanhol and Tomitsch (4) and Behrens et al (2) as: Mobile interface, performative interface, allotted interfaces, and responsive ambient interface.

\section{Visualisation Output}

1. Modality- Type of visualisation. Metrics: visual, tactile, olfactory, and auditory.

2.Information capacity- The number of information sources that ambient display can present. Metrics: low, medium, high.

3. Visual dynamics- The rate at which data and visuals changes. Metrics: low, medium, high.

\section{Data-triggered Social Interaction}

Social interaction in public display has been explored extensively, while only several studies emphasise on the impact of data properties and manifestation on public experience. Based on the previous work $(5)(11)(14)(18)$, the following lists main social phenomena evoked by displayed information. The influence is partitioned into two mingled aspects as "perceptional" and "behavioural" changes.

\section{Perceptional changes}

Before participation, people are motivated through the changes of their perception to display: Curiosity and incentives for engagement, collaboration, or competition. In "Honey-pot effect", arising curiosity from spectators plays as a key factor to maintain "action loop". According to Wouters et al (18), The effect is often related to the visibility of input actions and visualisation output. Exaggerative movement and vivid representation have more chances to attract public attention by its clash with surroundings $(8)(10)$. While the incentives for competition, based on the work from Valkanova et al (15), is mainly motivated by visualisation result. These are feedforward under the influence. However, during participation, chances are there to raise "social awkwardness" due to the fear of submitting inappropriate data. According to Valkanova et al (14), this feeling could be amplified by the identifiable personal visualisation.

\section{Behavioural changes}

Behavioural changes usually happen during the shift of roles between passers-by, spectators and participators (18). "Honey-pot effect" keeps the cycle of three roles and stimulate both active and passive engagement in the display (11). The passers-by turn into spectators by noticing the interactivity, and the spectators transfer to participators through input actions. After they quit interaction, they may have a discussion with new curious spectators about interaction rules (18). Although some audience are out of "action loop", they might get involved in the social discourse when the addressed topic is hyperlocal or there are discrepancies in understanding the projected information. "Social comparison" often happens between participators and spectators. It is more related to the type of data and visualisation style. Usually, physical and semantic data are more likely to trigger discourse as they are often related to a common issue or experience.

\section{Case studies}

To explore how these features in taxonomy support social interaction, we analysed existing projects that we identified as good examples. Drawing on the literature 


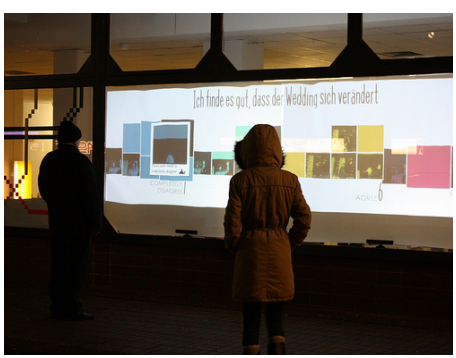

Figure 1: During participation, People decided to put photos on the tile after submitting his opinion in "My Position". (http://www.rwalter.de)

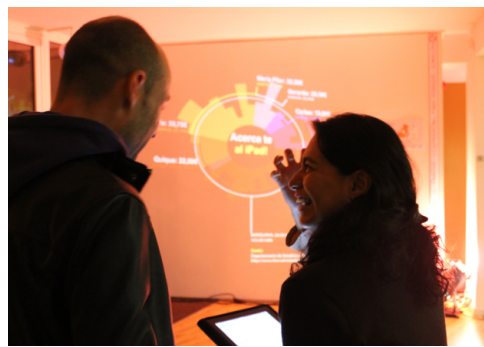

Figure 3: In "Reveal-it!", people submit data of individual energy consumption and average community usage through public input entry. (https://ai2-s2public.s3.amazonaws.com/figures /2017-08-

08/cfc5d97e1209bc4757ef9ebb8 1108a425448b97/5-Figure31.png) that outlines the project that we selected, we are able to gain an intensive understanding in its social effects. In the following section, we explain briefly the project component and highlight the corresponding changes on passers-by.

\section{My Position}

"My Position" is a large interactive poll visualisation aimed to support situated deliberation of citizen opinions. The visualisation is made of a series of square tiles, and each represents the opinion submitted by single participator. According to Valkanova et al (14), several goals have been achieved during projection: 1) Low barrier entry (simple gestures and guidance texts) and playful input action (Kinect sensed movements and options for photo taken) encouraged all participation and 2 ) it succeed at raising awareness of public opinions and sparking social debates.

\begin{tabular}{l|lll} 
Features & Component & $\begin{array}{l}\text { Perceptional } \\
\text { changes }\end{array}$ & $\begin{array}{l}\text { Behavioral } \\
\text { changes }\end{array}$ \\
\hline Info & Semantic & Understanding & $\begin{array}{l}\text { Discourse, } \\
\text { Spectating, } \\
\text { Participating }\end{array}$ \\
\cline { 1 - 3 } $\begin{array}{l}\text { Hyper- } \\
\text { locality }\end{array}$ & Hyperlocal & $\begin{array}{l}\text { Understanding } \\
\text { Social } \\
\text { Awkwardness }\end{array}$ & \\
\hline Input & Gestures & - & $\begin{array}{l}\text { Spectating, } \\
\text { Participating }\end{array}$ \\
\hline \begin{tabular}{l|lll} 
User \\
interface
\end{tabular} & Performative & Curiosity & \\
\hline Modality & Colored Tiles & - & $\begin{array}{l}\text { Discourse, } \\
\text { Comparison, } \\
\end{array}$ \\
& & & $\begin{array}{l}\text { Spectating, } \\
\text { Participating }\end{array}$
\end{tabular}

\begin{tabular}{l|ll}
$\begin{array}{l}\text { Info } \\
\text { capacity }\end{array}$ & $\begin{array}{l}\text { High- } \\
\text { cumulative }\end{array}$ & $\begin{array}{l}\text { Incentives } \\
\text { for } \\
\text { competition }\end{array}$ \\
\hline $\begin{array}{l}\text { Visual } \\
\text { dynamics }\end{array}$ & Medium & Curiosity \\
\hline
\end{tabular}

Table 1: The analysis of perceptional and behavioral changes triggered by data-supported features in "My Position".

Reveal-it!

"Reveal-it!" is an interactive public projection supporting comparison between energy consumptions of individuals and community averages (15). This project explores how communal data visualisation influence the user awareness, participation and discourse of differentiated understandings to the display. Valkanova et al concluded it successful in raising public awareness and stimuli discussion (14), yet, they also emphasized that there are difficulties in visualizing aggregated data as it may decrease public trust to projected information and lead to false input.

\begin{tabular}{|c|c|c|c|}
\hline Features & Component & $\begin{array}{l}\text { Perceptional } \\
\text { changes }\end{array}$ & $\begin{array}{l}\text { Behavioral } \\
\text { changes }\end{array}$ \\
\hline Info & Physical & Understanding & \multirow{2}{*}{$\begin{array}{l}\text { Discourse, } \\
\text { Comparison, } \\
\text { Spectating, } \\
\text { Participating }\end{array}$} \\
\hline $\begin{array}{l}\text { Hyper- } \\
\text { locality }\end{array}$ & Communal & $\begin{array}{l}\text { Curiosity } \\
\text { Social } \\
\text { Awkwardness }\end{array}$ & \\
\hline Input & Online Form & - & \multirow[t]{2}{*}{ Participating } \\
\hline $\begin{array}{l}\text { User } \\
\text { interface }\end{array}$ & Mobile & - & \\
\hline Modality & $\begin{array}{l}\text { Polar } \\
\text { diagram }\end{array}$ & $\begin{array}{l}\text { Incentives for } \\
\text { competition }\end{array}$ & \multirow{3}{*}{$\begin{array}{l}\text { Discourse, } \\
\text { Comparison, } \\
\text { Spectating, } \\
\text { Participating }\end{array}$} \\
\hline $\begin{array}{l}\text { Info } \\
\text { capacity }\end{array}$ & $\begin{array}{l}\text { High- } \\
\text { cumulative }\end{array}$ & $\begin{array}{l}\text { Incentives for } \\
\text { competition, } \\
\text { Decreased trust }\end{array}$ & \\
\hline $\begin{array}{l}\text { Visual } \\
\text { dynamics }\end{array}$ & $\begin{array}{l}\text { Low to } \\
\text { medium }\end{array}$ & - & \\
\hline
\end{tabular}




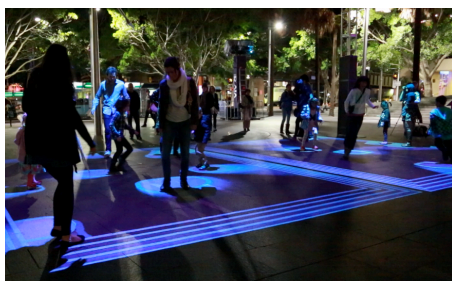

Figure 3: In "Solstice LAMP", people play with their avatar-like representation solely or collaboratively. Shapes of polygon change with user movement and merge into bigger one when people get close. (http://www.martintomitsch.com

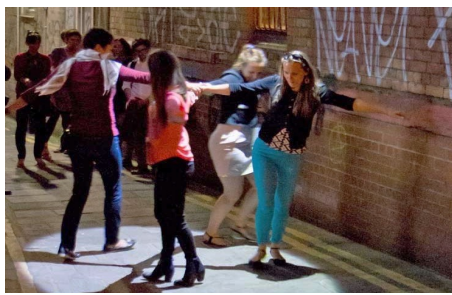

Figure 4: In "Shadowing", people submit playful movement under street lights embedded with motion-capture sensors. Sometimes they play with their shadows after submission.

(https://www.playablecity.com )
Table 2: The analysis of perceptional and behavioral changes triggered by data-supported features in "Reveal-it!".

\section{Solstice LAMP}

"Solstice LAMP" is an interactive installation deployed in Vivid Sydney 2013. The display enables passers-by to generate their own avatar animation and sounds that travel up to building facades by peculiar sonic and visual technologies. Based on the field study conducted by Hespanhol and Tomitsch (4), vivid projection attracts much public attention, and intuitive input actions in allotted interface enabled quick

understandings and participation from spectators. According to their observation (4), multi-use mode in the display to some extent encouraged negotiations or further collective activities between strangers.

\begin{tabular}{|c|c|c|c|}
\hline Features & Component & $\begin{array}{l}\text { Perceptional } \\
\text { changes }\end{array}$ & $\begin{array}{l}\text { Behavioral } \\
\text { changes }\end{array}$ \\
\hline Info & Customised & Curiosity & \multirow[t]{2}{*}{$\begin{array}{l}\text { Spectating, } \\
\text { Participating }\end{array}$} \\
\hline $\begin{array}{l}\text { Hyper- } \\
\text { locality }\end{array}$ & Irrelevant & - & \\
\hline Input & $\begin{array}{l}\text { Full-body } \\
\text { movement }\end{array}$ & Curiosity & \multirow{2}{*}{$\begin{array}{l}\text { Discussion, } \\
\text { Spectating, } \\
\text { Participating }\end{array}$} \\
\hline $\begin{array}{l}\text { User } \\
\text { interface }\end{array}$ & Allotted & - & \\
\hline Modality & $\begin{array}{l}\text { Flexible } \\
\text { polygons }\end{array}$ & Curiosity & \multirow{3}{*}{$\begin{array}{l}\text { Discussion } \\
\text { Spectating, } \\
\text { Participating }\end{array}$} \\
\hline $\begin{array}{l}\text { Info } \\
\text { capacity }\end{array}$ & $\begin{array}{l}\text { High- } \\
\text { Real-time }\end{array}$ & $\begin{array}{l}\text { Incentives for } \\
\text { collaboration }\end{array}$ & \\
\hline $\begin{array}{l}\text { Visual } \\
\text { dynamics }\end{array}$ & High & Curiosity & \\
\hline
\end{tabular}

Table 3: The analysis of perceptional and behavioral changes triggered by data-supported features in "Solstice LAMP".

\section{Shadowing}

Shadowing is an interactive lighting installation published by Chomko and Rosier. It gives memory to city street lights, enabling them to record and play back the shadows of pedestrians who passed underneath. According to the study from Anton (1), it succeeds at using simple input entry to attract diverse participation, and dynamic shadow encourages creative contributions. Based on the recordings from Chomko and Rosier (1), during display, passers-by are paused to watch playful shadows contributed by last user, further many of them participate in creating new shadows. The observation indicates that some users tend to play with their own shadows and make repetitive submission.

\begin{tabular}{|c|c|c|c|}
\hline Features & Component & $\begin{array}{l}\text { Perceptional } \\
\text { changes }\end{array}$ & $\begin{array}{l}\text { Behavioral } \\
\text { changes }\end{array}$ \\
\hline Info & Customised & Curiosity & \multirow{3}{*}{$\begin{array}{l}\text { Discussion } \\
\text { Spectating, } \\
\text { Participating }\end{array}$} \\
\hline & & & \\
\hline $\begin{array}{l}\text { Hyper- } \\
\text { locality }\end{array}$ & Irrelevant & - & \\
\hline Input & $\begin{array}{l}\text { Full-body } \\
\text { movement }\end{array}$ & - & \multirow[t]{2}{*}{$\begin{array}{l}\text { Spectating, } \\
\text { Participating }\end{array}$} \\
\hline $\begin{array}{l}\text { User } \\
\text { interface }\end{array}$ & Performative & $\begin{array}{l}\text { Incentives for } \\
\text { participation }\end{array}$ & \\
\hline Modality & $\begin{array}{l}\text { Shadows } \\
\text { movement }\end{array}$ & Curiosity & \multirow{3}{*}{$\begin{array}{l}\text { Discussion, } \\
\text { Spectating, } \\
\text { Participating }\end{array}$} \\
\hline $\begin{array}{l}\text { Info } \\
\text { capacity }\end{array}$ & $\begin{array}{l}\text { Low- } \\
\text { Temporary }\end{array}$ & $\begin{array}{l}\text { Incentives for } \\
\text { participation }\end{array}$ & \\
\hline $\begin{array}{l}\text { Visual } \\
\text { dynamics }\end{array}$ & Medium & - & \\
\hline
\end{tabular}

Table 4: The analysis of perceptional and behavioral changes triggered by data-supported features in "Shadowing". 


\section{Findings and Discussion}

The main findings of the case studies indicate that, different data-based features supporting different social experiences:

The rising of perceptional changes is mainly evoked by displayed content and data manifestation. Physical and semantic information could be easily accepted and understood by the public, while the customised content arises more curiosities. The more pedestrians are related to topic, the more concerns they show to the display. However, it may lead to the negative effect "Social awkwardness"- Since content is shared with local community or large audience, some potential participators are held back by the fear of submitting inappropriate data in front of public (14). Visualisation output stimulates perceptional changes by information capacity and temporality. In "My position" and "Reveal it!", the accumulated projection of personal information leads to comparison between participators, and to some extent, it also motivates spectators to join the competition (16). While for customised display, people are encouraged to crate identifiable content instead of setting up competition. Besides, the dynamic projection maintains sustainable attractions to spectators.

According to the analysis, perceptional changes evoked by data-based features further encourage different behavioural changes. In "Reveal it!", accumulative projection of personal data causes differentiated understandings which leads to social comparison and discourse (15). While the curiosity for customised content has more chances to raise social talk or discussion, as shown in "Solstice LAMP" (4). Input technologies trigger curiosity and participation through exaggerative input actions or the real-time interactivity between user input and interfaces. Compared with mobile or distributed devices, Public interfaces or screens with interfaces embedded could acknowledge the public of interactivity easily. For display output, rich visual style of aggregated information incentivizes competition or collaboration, while real-time display attracts more curiosity and casual participation.

\section{Conclusion}

In this paper, we explored the role of data in the ambient display and its impact on social interactions. The results suggest, the addressed topic not only defines the main content of display, but also has a great influence on maintaining the spectator curiosities. due to its social relevance of topic. Input technology plays a significant role in supporting pedestrians' notice of display interactivity and further participation. For output, besides attracting attention, it also affects public understandings of display. Further studies need to be carried out in uncovering connections between data-supported experience and contextual factors. In particular, we want to know under different context, how data-related features influence social interaction.

\section{References}

1. Anton, N. (2017). Playable Cities, The City as a Digital Playground. Springer

2. Behrens, M., Fatah gen. Schieck, A., and Brumby, D. (2015). Designing Media Architectural Interfaces for Interactions in Urban Spaces. In M. Foth, M. Brynskov, T. Ojala (Eds.), Citizen's Right to the Digital City: Urban Interfaces, Activism, and Placemaking (pp. 55-77). Singapore: Springer. doi:10.1007/978-981-287-919-6_4

3. Claes, S., and Vande Moere, A. (2104). What Public Visualiation Can Learn from Street Art. Proceedings 
of the IEEE VIS 2014 Arts Program, VISAP'14: Art+ Interpretation, Paris, France, November 2014

4. Hespanhol, L., and Tomitsch, M. (2015). Strategies for Intuitive Interaction in Public Urban Spaces. Interacting with Computers, 2015, Vol. 27(3), pp.311-326

5. Keskinen, T., Hakulinen, J., Heimonen, T., Turunen, M., Sharma, S., Miettinen, T., \& Luhtala, M. (2013). Evaluating the experiential user experience of public display applications in the wild.

Proceedings of the 12th International Conference on Mobile and Ubiquitous Multimedia, MUM'13.

6. Koeman, L. (2014). An Exploratory Study into the Public and Situated Visualisation of Local Data in Urban Communities. In Proceedings of the 2014 Companion Publication on Designing Interactive Systems (DIS '14), pages 173-176.

7. Matthews, T., Rattenbury, T., Carter, S., K. Dey, A., \& Mankoff, J. (2003). A peripheral display toolkit. Technical Report No. UCB/CSD-03-1258.

8. Muller, J., Walter, R., Bailly, G., Nischt, M., \& Alt, F. (2012). Looking Glass: A Field Study on Noticing Interactivity of a Shop Window. CHI 2012, May 510, 2012, Austin, Texas, USA

9. M. Netto, V., Brigatti, E., Meirelles, J., Ribeiro, F. Pace, P., Cacholas, C., \& Sanches, P. (2018). Cities, from information to interaction, July 3, 2018

10. Nemanja, M., Fatah gen. Schieck, A., M. Schnadelbach, H., Kostopoulou, E., North, S., \& Ye, L. (2015). Capture the Moment: "In the Wild" Longitudinal Case Study of Situated Snapshots Captured Through an Urban Screen in a Community Setting. Proceedings of the 18th ACM Conference on Computer Supported Cooperative Work \& Social Computing (Vancouver, BC, Canada -March 14 - 18, 2015), CSCW '15, pages 242-253

11. Nemanja, M., Langheinrich, M., Alt, F., Elhart, I., Hosio, S., \& Rubegni, E. (2012). Using Public Displays to Stimulate Passive Engagement, Active
Engagement, and Discovery in Public Space. In Proceedings of the 4th Media Architecture Biennale Conference, 15 November 2012, pages 55-64

12. Pousman, Z., and Stasko, J. (2006). A Taxonomy of Ambient Information Systems: Four Patterns of Design. In Proceedings of the working conference on Advanced visual interfaces (Venezia, Italy, May 23 - 26, 2006), AVI '06, ACM New York, NY, 67-74

13. Tomitsch, M., Kappel, K., Lehner, A., \& Grechenig, T. (2007). Towards a Taxonomy for Ambient Information Systems. Ambient Information Systems. 200744.

14. Valkanova, N., Jorda, S., \& Vande Moere, A. (2015). Public visualization displays of citizen data: Design, impact and implications, International Journal of Human - Computer Studies. September 2015, Vol.81, pp.4-16

15. Valkanova, N., Jorda, S., Tomitsch, M., \& Vande Moere, A. (2013). Reveal-it!: The Impact of a Social Visualization Projection. Proceedings of the SIGCHI Conference on human factors in computing systems, 27 April 2013, pp.3461-3470

16. Vande Moere, A., Tomitsch, M., Wimmer, C., Christoph, B., \& Grechenig, T. (2012). Evaluating the effect of style in information visualization. IEEE transactions on visualization and computer graphics, 18(12), 2739-2748.

17. Wouters, N., Claes, S., \& Vande Moere, A. (2015). Investigating the role of situated public displays and hyperlocal content on place-making. Interaction Design and Architecture(s) Journal IxD\&A. No.25, 2015, pages 60-72

18. Wouters, N., Downs, J., Harrop, M., Cox, T. Oliveira, E., Webber, S., Vetere, F., \& Vande Moore, A. (2016). Uncovering the Honeypot Effect: How Audiences Engage with Public Interactive Systems, Proc. of the 2016 Conference on Designing Interactive Systems, DIS '16, June 0408, 2016, Brisbane, QLD, Australia 